\title{
Recent advances in Brucella abortus vaccines
}

\author{
Elaine MS Dorneles ${ }^{1}$, Nammalwar Sriranganathan ${ }^{2}$ and Andrey P. Lage ${ }^{1 *}$
}

\begin{abstract}
Brucella abortus vaccines play a central role in bovine brucellosis control/eradication programs and have been successfully used worldwide for decades. Strain 19 and RB51 are the approved B. abortus vaccines strains most commonly used to protect cattle against infection and abortion. However, due to some drawbacks shown by these vaccines much effort has been undertaken for the development of new vaccines, safer and more effective, that could also be used in other susceptible species of animals. In this paper, we present a review of the main aspects of the vaccines that have been used in the brucellosis control over the years and the current research advances in the development of new $B$. abortus vaccines.
\end{abstract}

\section{Table of contents}

1. Introduction

2. Vaccines, vaccination and their use in brucellosis control and eradication programs

3. S19 vaccine

4. RB51 vaccine strain

5. $45 / 20$ vaccine

6. SR82 vaccine strain

7. Vaccination with recombinant genes, proteins, vectors and $B$. abortus recombinant mutants

7.1. DNA vaccines

7.2. Subunit vaccines

7.3. Vector vaccines

7.4. B. abortus recombinant mutants

8. Other B. abortus potential vaccines

9. Conclusions

10. Abbreviations

11. Competing interests

12. Authors' contributions

13. Acknowledgements

14. References

\section{Introduction}

B. abortus is the main causative agent of brucellosis in cattle, causing abortion and infertility in adult animals [1]. Bovine brucellosis is a worldwide zoonotic disease,

\footnotetext{
* Correspondence: alage@vet.ufmg.br

'Departamento de Medicina Veterinária Preventiva, Escola de Veterinária, Laboratório de Bacteriologia Aplicada, Universidade Federal de Minas Gerais, Belo Horizonte, MG, Brazil

Full list of author information is available at the end of the article
}

endemic in some regions of the world such as Latin America, Middle East, Africa and Asia [1] and responsible for large economic losses due to animal and human health problems.

Due to public health importance of brucellosis and the damage that it causes to the livestock industry, much effort has been expended to control and eradicate the disease in cattle. The development of an efficacious vaccine for brucellosis control/eradication has been a challenge for scientists for many years. Despite enormous advances and the development of B. abortus S19 and RB51 vaccines, the search for improved vaccines has never ends. Although the available vaccines are effective in controlling brucellosis, they have numerous drawbacks, such as interference with diagnostic tests, pathogenicity for humans, potential to cause abortion in pregnant animals, among others. In this paper, we present a review of the main aspects of the vaccines that have been used in the bovine brucellosis control and eradication over the years and some of the current advances in the research for a new B. abortus vaccine.

\section{Vaccines, vaccination and their use in brucellosis control and eradication programs}

According to Schurig et al. [2] and Ko and Splitter [3], an ideal vaccine against brucellosis should possess the following characteristics: (i) be live and able to provide a strong type $1 \mathrm{~T}$ helper immune response (Th1); (ii) do not induce antibodies that interfere with the serological tests employed in the diagnosis of infected cattle, regardless of route, dose of administration, age or sex of the animals; (iii) be attenuated and do not cause disease or 
persistent infection in immunized animals nor be pathogenic for humans; (iv) be able to induce a strong and long-lasting protection against systemic and uterine infection, besides preventing abortion, even in pregnant animals inoculated with a single dose; (v) do not lead to seroconversion on revaccination; (vi) be stable and do not revert virulence in vivo nor in vitro; and (vii) be inexpensive, easy to produce and to administer.

Even though we still do not have an ideal vaccine, vaccination with available vaccine strains remains the most successful method for the prevention and control of brucellosis in cattle, being a critical component of most brucellosis control and eradication programs throughout the world [4]. Numerous countries have adopted control measures against bovine brucellosis in order to reduce the prevalence or eradicate the disease from domestic livestock, in an effort to prevent transmission to humans and mitigate economic losses. Vaccination of female calves is the central point of any brucellosis control program, since it has performed well in the reduction of disease prevalence, therefore useful at the disease control stage. Considering that vaccination alone is not enough to control and eradicate the disease, it should be associated with continuous elimination of infected animals, as they are the source of new infections. Thus, besides vaccination, most bovine brucellosis eradicate programs also include test-and-slaughter policies, surveillance and hygiene measures [4].

The aim of vaccination is the reduction of susceptibly individuals in the population and the success of any vaccination program depends mainly on the effectiveness of the vaccine used and its coverage in the target population. Vaccines against brucellosis have been evaluated with respect to their potency by three different approaches: (i) testing in laboratory animals or (ii) testing in natural hosts experimentally challenged and (iii) testing under natural conditions [5]. Of these, test in natural hosts shows more significant response and is the only one able to measure the efficacy of $B$. abortus vaccines [6,7]. In experimental studies of vaccine efficacy, vaccinated and non-vaccinated controls will receive a known infectious dose of a virulent $B$. abortus strain at the most susceptible period (mid-gestation), and the protection is measure by the ability of the vaccine in preventing abortion [4]. However, it is important to emphasize that the experimentally obtained effectiveness may differ from field efficacy that can be influenced by other factors, such as nutrition, environmental stress, age at vaccination, vaccination management or immunological status [4]. Besides, the above three classical methodologies, B. abortus vaccines could also be assessed by measuring the immune responses and determination of correlates of protection by mathematical modeling. The identification of protection markers can be an useful approach to screen vaccine candidates whether validated by vaccine potency tests [8]. Since experiments involving challenge of pregnant cattle are very expensive, time-consuming and requires large animal biosafety level 3 facilities, the rational way for the future of $B$. abortus vaccines testing and development could be the characterization and identification of the correlates of protection.

Another important aspect related to the success of brucellosis control programs is the quality of the vaccine used. Despite the cost of the vaccine being just one fraction of the total cost of a control program, its quality will affect directly and dramatically the outcome of the program. Assessing the quality of live Brucella vaccines is usually based on in vitro criteria, including physico-chemical and microbiological in vitro tests as to purity, dissociation, and determination of $\mathrm{pH}$, humidity and count of viable bacteria [9]. Recently, genetic stability has also been proposed as an additional criterion in assessing of the quality of Brucella spp. vaccines [10-12]. Although less frequently, immunogenicity in mouse can also be included in Brucella vaccines tests, however not having cutoff points (protection zone) defined for RB51 vaccine [9-11] and as mouse immune system does not accurately represent bovine immune system, it is very difficult to use such data.

Attenuated $B$. abortus strains have demonstrated the best results in the prevention of bovine brucellosis. $B$. abortus live modified vaccines are highly effective in decreasing transmission and production losses caused by brucellosis, but are less effective at preventing infection by field strains [4]. Since, abortion is the key for the brucellosis transmission in cattle, a vaccine that can effectively prevent abortion is able to reduce disease transmission and largely reduce economic losses caused by the disease. Immunization with live modified $B$. abortus vaccines is generally performed in young female calves in a single dose by intramuscular or subcutaneous injection [5]. However, in zones of high prevalence of brucellosis, massive vaccination, including adult cows, is performed.

It is also important to take into account that although cattle are the main target of the vaccination against $B$. abortus within bovine brucellosis control and eradication programs, they are not the unique species infected by this agent. Goats, feral swine, elks, bison and other hosts can also be infected by B. abortus and some of them are even able to sustain the disease, being considered an important source of the re-emergency of the disease in cattle [1].

Only a few vaccines have been used massively in cattle immunization against B. abortus, S19, RB51, 45/20 and SR82, being S19 and RB51 the most widely used vaccines [4]. However, many B. abortus vaccine candidates have been developed, including DNA, subunit, recombinant $B$. abortus and recombinant vector vaccines. All of them are evaluated principally in mouse model [13-46], 
and with a few exceptions, the majority of these new vaccines, have not been tested in cattle or were not protective in cattle, the target species.

\section{S19 vaccine}

Strain 19 is a live attenuated vaccine and the first B. abortus vaccine to be used extensively for bovine brucellosis control [47]. In USA, this vaccine was used for more than five decades from 1941 and is still being used in several other countries [4].

Brucella abortus S19 was isolated in 1923 from milk of a Jersey cow by Dr John Buck [48]. This virulent culture was accidentally left out at room temperature for one year and when tested in guinea pigs showed lower virulence compared with previous tests [49]. Subsequently, S19 showed to be highly successful in immunization of calves $[48,50]$. The efficacy of $B$. abortus S19 was proved by experimental tests in cattle $[47,51]$ and under field conditions [5,52]. Its main characteristics are stable low pathogenicity, relatively high immunogenicity, and moderate antigenicity [53]. Strain 19 is a smooth attenuated $B$. abortus biovar 1 that induces antibody response that cannot be distinguished from the antibody response induced by infection with field strains $[4,50]$. The lipopolysaccharide (LPS) O-side chain is an immunodominant antigen to which the majority of antibodies resulting from S19 immunization or natural infection are directed [54]. Antibody titers resulting from vaccination may persist for a prolonged period in a small proportion of vaccinated calves: approximately two animals per 100000 calfhood vaccinated ones [54]. Residual antibody titers increase with the age at which the animal was vaccinated [5], and to address this issue, vaccination is usually performed on young female calves between three and eight months of age [47]. However, vaccination of this age group does not appear to significantly differ in immunity induced [47]. Restriction on age of vaccination, due to the interference in the brucellosis diagnosis, is the main disadvantage of vaccination with S19. This has contributed greatly to their replacement by RB51 vaccine strain, which does not have this problem.

In calves, S19 vaccination can be performed with full dose $\left[2.5-12 \times 10^{10}\right.$ colony forming units (CFU)], original dosage used in S19 classical experiments, or with reduced dosage $\left(3-10 \times 10^{9} \mathrm{CFU}\right)$ to minimize residual antibody titers and to prevent occasional persistent vaccinal infection [4]. After calfhood-vaccination, S19 is usually cleared from superficial cervical lymph node within 10 to 12 weeks. Vaccination of adult cattle with S19, low dosage $\left(0.3-3 \times 10^{9} \mathrm{CFU}\right)$, was also successfully employed in infected herds [5,55,56]. S19-adult vaccination was tested as a strategy to be used in infected herds in order to reduce abortions and subsequently brucellosis transmission; however, it was discontinued because vaccination of pregnant animals can cause abortion and mainly because of the persistence of vaccinal antibodies $[56,57]$.

In general, after calfhood vaccination, S19 does not persist in the reproductive tracts of mature heifers and does not cause abortion in these animals [54]. Nonetheless, even with markedly infrequent occurrence, some cattle remain chronically infected and may abort and excrete the vaccine strain in the milk. Another disadvantage of S19 vaccination includes the fact that in some circumstances S19 can cause abortion in pregnant animals [57]. After vaccination of cattle with one, two or three doses prior to breeding age, McDiarmid [51] recovered S19 from 10\% of milk samples and 1.5\% of samples from cases of abortion. In males, calfhood S19 vaccination usually results in persistent antibody titers, testicular infection, and hence infertility [58]. Furthermore, the vaccination of infected animals with S19 does not cure nor alter the normal course of the disease $[47,50]$.

On the other hand, duration of immunity induced by S19 in cattle vaccinated as calves has proven to be quite long, reaching almost the entire productive lifespan of the animal $[47,51]$. The immunity in cattle vaccinated between 6 and 8 months of age does not decrease from the first through the fifth pregnancy [47,51]. Moreover, revaccination experiments with S19 and killed B. abortus vaccines demonstrated no apparent benefit in cattlechallenge experiments compared with just S19-calfhood immunization [47], despite McDiarmid [51] having observed a small gain from S19 revaccination. Under field conditions 82 to $95 \%$ of vaccinated cattle have been shown to have complete protection against infection with virulent strains [50]. However, it has also been demonstrated that the effectiveness of the vaccine decreases proportionally with an increasing dose of bacterial exposure [47,50].

Regarding the immune response triggered by S19 vaccination, most of our knowledge comes from mice studies, which have been shown a strong Th1 immune response with production of IFN- $\gamma$ and high levels of antigen-specific $\mathrm{CD}_{4}^{+}$and granzyme $\mathrm{B}$-secreting $\mathrm{CD} 8^{+}$ T-cell responses [32].

Being pathogenic to man, the utilization of S19 requires safety training of the personal involved and the use of personal protection equipment as gloves, long sleeve coats, protection glasses, and N95 masks.

\section{RB51 vaccine strain}

$B$. abortus strain RB51 is a rough rifampicin-resistant strain, which exhibited a lack of expression of the LPS Oside chains (OPS) [59]. RB51 vaccine strain was developed in 1982 by Prof. Gerhardt Schurig's group and is derived from a virulent smooth $B$. abortus biovar 1 strain 2308 [59]. This is a natural mutant derived by a serial 
passages on media containing subinibitory concentrations of rifampicin or penicillin and by selecting single colonies with rough morphology [59]. The rough characteristic is stable during in vitro and in vivo passages and does not revert to virulent phenotype [59].

The protection against abortion and infection induced by RB51 vaccination in cattle has been sufficiently demonstrated under experimental conditions [6,7,60,61,64]. Also, the use of RB51 is highly effective under field conditions, in herds with high and low brucellosis prevalence $[62,63]$.

The literature shows that calves vaccinated with RB51 at three, five and seven months of age are protected against infection and abortion [64], as well as heifers vaccinated at age of 10 or 24 months, after challenge with the virulent $B$. abortus $2308[6,60]$. Nevertheless, it has been suggested that under experimental circumstances the vaccination with S19 is slightly (not significant) more efficacious than RB51 [4,64]. After vaccination, RB51 is usually cleared from calf superficial cervical lymph node within 6 to 10 weeks [64]. RB51 is considered more attenuated than S19, based on results of clearance and histologic examination of infected tissues of vaccinated animals.

In general, the recommended dosage for RB51 calfhood vaccination is $1.0-3.4 \times 10^{10} \mathrm{CFU}$ [4]. Protection against $B$. abortus infection is similar through the suggested dosage, although higher antibody titers and longer persistence of bacteria had been associated with the full dose $\left(3.4 \times 10^{10} \mathrm{CFU}\right)$ [8]. Reduced dosage $\left(1 \times 10^{9} \mathrm{CFU}\right)$, generally recommended for adult animals, also protects against infection and abortion caused by virulent 2308 [61]. Despite RB51 having highly reduced abortifacient characteristics [59,65], it is not completely safe for pregnant cow, mainly when full dose is administrated [66]. However, some results indicate that nonvaccinated cattle and cattle vaccinated with $\mathrm{S} 19$ as calves can be safely vaccinated with RB51 (full dose) during the pregnancy $[6,67,68]$. Furthermore, data indicates that RB51 vaccination is a safe procedure also for males [69].

In addition, as S19 vaccine, RB51 can cause infection in humans especially immunosuppressed individuals [70]. RB51 is resistant to rifampicin, one of the antibiotics of choice in the treatment of human brucellosis, and failure to be detected by routine serological tests are the two most important points one has to be aware during diagnosis and treatment of humans. Therefore, the same protective measures recommended for S19 also applies to RB51 use.

Because of the rough phenotype, RB51 does not induce the production of anti-OPS antibodies in immunized animals, overcoming the serologic problems observed after S19 vaccination [7,59,61]. Consequently, RB51 vaccinated cattle can be easily and accurately differentiated from naturally infected animals, allowing the effective use of the test-and-slaughter and vaccination policies simultaneously. Vaccination with RB51 does not induce antibodies detectable by routine serologic brucellosis diagnostic tests, even after S19 calfhood vaccination and multiple RB51 boosters or use of full dose of RB51 $\left(3.4 \times 10^{10}\right.$ CFU $) \quad[7,61,68]$. However, RB51-specific antibodies can be detected by dot enzyme-linked immunosorbent assay or ELISA using killed RB51 antigens [71,72], until approximately 12 weeks after vaccination, with the peak occurring four weeks after vaccination or revaccination with decreasing titers after ten weeks [61,73]. Interestingly, S19-vaccinated cattle exhibit higher titers against RB51 antigens in ELISA than animals vaccinated with RB51, probably due to persistence of S19, which may result in high levels of cross-reacting antibodies against RB51 antigens [73].

So far, there are no experiments that evaluated the duration of immunity, but Olsen and Stoffregen [4] suggest that a booster vaccination is required between 4 and 5 years of age to maintain high levels of protection after RB51 calfhood vaccination. Also, RB51 revaccination has been recommended six months and one year after calfhood vaccination in northern Mexico [74]. Nonetheless, findings from blastogenic response of $\mathrm{CD}^{+}$and $\mathrm{CD} 8^{+} \mathrm{T}$ cells and the production of IFN- $y$ and IL- 4 by the lymphocyte subsets six months after RB51 revaccination indicate that there was no increase or improvement in the immunological response resulting from RB51-revaccination of adult cattle [75]. Even though, RB51 revaccination may still be considered as a tool for increasing herd immunity, since not all animals are completely protected after primary immunization [50]. Furthermore, it has been demonstrated that RB51 induces a strong Th1 cellular immune response with production of IFN- $\gamma$ and $\mathrm{CD}^{+}$specific cytotoxic cells, but not IL-4 after vaccination of mice [76].

\section{45/20 vaccine}

This vaccine is prepared with heat-killed $B$. abortus biovar 1 strain 45/20 combined with oil adjuvant [77]. The $45 / 20$ is a rough $B$. abortus, derived of smooth strain $45 /$ 0 after 20 passages through guinea pigs [78]. This bacterin was used in some European Union countries for $B$. abortus control replacing S19, in order to eliminate the problems related to the induction of antibodies interfering in the routine diagnosis of infection [5]. However, data of experimental efficacy and immunologic response are contradictory and mostly show the superiority of vaccination with S19 $[79,80]$. Furthermore, its use has some drawbacks such as the use of oil adjuvant, needing of repeat vaccination and reversion to smooth strain when used as a live vaccine [5,78]. Furthermore, some studies have also indicated that $45 / 20$ is not completely free of the $\mathrm{O}$-side chain [81], hence this vaccine can induce antibodies detectable by routine serologic tests employed in 
the diagnosis of bovine brucellosis. The variability in reported protection, along with unpredictable serological effects and the occurrence of reactions at the site of vaccine injection in some animals led to the interruption of the use of $45 / 20$ vaccine.

\section{SR82 vaccine strain}

The SR82 strain is a B. abortus biovar 6 live attenuated vaccine used since 1974 by the former Union of Soviet Socialist Republics (USSR) for bovine brucellosis control [82]. This vaccine agglutinates in both rough and smooth anti-sera, but does not induce positive response in brucellosis agglutination tests $[82,83]$. Moreover, SR82 induced protection level similar to S19, after challenge with virulent $B$. abortus, and it has been shown to be effective under field conditions $[82,83]$. Currently the SR82 strain is still massively used in the Russian Federation, Azerbaijan, Tejikistan and other countries in the region [82].

\section{Vaccination with recombinant genes, proteins, vectors and $B$. abortus recombinant mutants}

Classically and historically the vaccines used in the bovine brucellosis control are live attenuated vaccines produced from spontaneously attenuated or randomly selected strains. Nonetheless, the numerous advances in genomics, proteomics, recombinant DNA technology and even in vaccinology, allowed the exploration of other tools for the development of safer vaccines, without drawbacks observed in classical vaccines. In this context, several studies aimed to develop, test the efficacy or assess the immulogical responses of the $B$. abortus genetically engineered vaccines (recombinant genes, proteins, vectors and modified $B$. abortus strains) have been performed essentially in mice. However, with a few exceptions the majority of these recombinant vaccines, have not been tested or did not protect cattle, their target species. Moreover, it is important to take into account that recombinant vaccines, especially non-living ones, have limitations regarding economic viability, need for multiple doses and the need for combination of antigens.

\subsection{DNA vaccines}

DNA vaccines offer the possibility of inducing both cellular and humoral responses, expression of antigens is prolonged, they have better stability and do not require refrigeration under storage. Therefore, several antigens have been explored for their value as DNA vaccines against $B$. abortus challenge, providing various levels of protection. DNA vaccines encoding ribosomal $L 7 / L 12$, lumazine synthase $(B L S)$, P39 (a putative periplasmic binding protein), Omp16 (outer membrane protein) and BAB1_0278 genes have demonstrated to confer protection against $B$. abortus challenge in mice $[22,23,27,42]$. Moreover, $\mathrm{Cu} / \mathrm{Zn}$ superoxide dismutase $(\mathrm{Cu}-\mathrm{Zn}$ SOD) DNA vaccine induced a protection level similar to the one induced by RB51 [25]. All these genes also proved capable of eliciting a desirable cellular immune response in mice [22,23,32,33,42]. In contrast, plasmid DNA carrying the BAB1_0263 and bacterioferritin $(B F R)$ genes did not induce significant level of protection against challenge with virulent $B$. abortus in mice.

Combined DNA vaccines have also demonstrated their ability to protect better against challenge. DNA vaccines of genes coding for an immundominant Brucella-antigen (BCSP31) and promising Brucella-antigens (SOD and L7/ L12) provided significantly better protection than S19 in mice [32]. This combined DNA vaccine also elicited significantly higher cytotoxic response (granzyme B-producing $\mathrm{CD}^{+} \mathrm{T}$ cells) compared to S19-vaccinated mice [32]. Likewise, divalent fusion DNA vaccine encoding $L 7 / L 12$ and Omp16 genes also proved to be effective and able to elicit a strong $\mathrm{T}$-cell proliferative response and induce a large amount of IFN- $\gamma$ producing $\mathrm{T}$ cells [27]. Additionally, data showed that combination of these $B$. abortus genes (BCSP31, SOD and L7/L12) with Mycobacterium tuberculosis (Ag85B, MPT64, and MPT83) or Mycobacterium bovis (Ag85B, MPT64, and MPT83) genes are very promising for both agents $[33,34]$. DNA vaccine containing six genes encoding immunodominant antigens from $M$. bovis and B. abortus induced protection comparable to S19 and better than Bacillus Calmette-Guerin (BCG) vaccine in cattle, suggesting that this is a highly promising vaccine for both diseases [34]. Combined DNA vaccine containing $M$. tuberculosis and B. abortus genes with added IL-12 adjuvant system showed that besides the high level of protection, IL-12 acts as an adjuvant to enhance protective immunity against $M$. tuberculosis and $B$. abortus in challenge mice [33]. Conversely, results suggest that a SOD DNA vaccine fused to IL-2 did not improve protection efficacy [29].

However, despite some of $B$. abortus DNA vaccine candidates have shown very promising results in mice, the need of at least four booster vaccinations to be effective as well as the high cost for use in large animals, make this type of vaccine impractical for cattle, the main target of brucellosis vaccination. Moreover, excluding mouse studies practically no DNA vaccine has been explored in natural hosts.

\subsection{Subunit vaccines}

Many of the same antigens tested as DNA vaccines have also been evaluated as potential antigens for subunit vaccines (L7/L12 ribosomal protein; P39; BLS; Omp16; $\mathrm{Cu} / \mathrm{Zn}$ SOD) $[14,21,24,37,40]$. The outer membrane proteins (OMPs) of B. abortus, potential immunogenic antigens, have been widely explored as subunit vaccines $[37,39,43,45]$. Unlipidated recombinant Omp16 and Omp19, and recombinant Omp25 liposome encapsulated gave protection comparable to S19 in vaccinated 
mice following challenge $[37,39,45]$. Also, Omp28 subunit vaccine increased resistance against challenge with virulent $B$. abortus but at lower level than live attenuated vaccines [43].

Similarly, flagellar proteins have been screened in search for a subunit vaccine antigen candidate. Five flagellar genes, although Brucella spp. are non-motile, (BAB1_0260 (Flg)); BAB2_0122 (FliN); BAB2_0150; BAB2_1086; BAB2_1093) were evaluated for their ability to induce humoral and cell-mediated responses and protect mice against $B$. abortus challenge [84]. Of these, FlgJ and FliN were found to be protective antigens that produced humoral and cellmediated responses in mice.

Moreover, recombinant proteins of other proven or putative pathogenesis-associated genes such as L7/12, BLS, rSurA and rDnaK induced different levels of protective immunity and cellular immune response in mice against brucellosis $[14,24,31]$. Whereas, dihydrolipoamide succinyltransferase (rE2o) and cysteine synthase A (rCysK) provided partial protection against $B$. abortus challenge and induced primarily Th2 type of immune response [41,46]. Furthermore, CobB, AsnC and P39 elicit protective immunity similarly to $\mathrm{Cu} / \mathrm{Zn} \mathrm{SOD}$ and S19, which is marked by both humoral and cellular immune responses $[21,85]$. Also, $\mathrm{Cu} / \mathrm{Zn}$ SOD recombinant protein (liposomes encapsulated) confers resistance in mice, further increased upon co-immunization with recombinant IL-18 [40]. In contrast, BAB1_0560, BAB1_1108, BAB2_0059 (VirB10), BAB2_0191, BAB2_0423 (GntR) and BRF protein vaccines did not induce protective immune response [21,85].

The potential use of $B$. abortus subunit vaccines under field conditions is very limited, although some encouraging results showed. The requirement of multiple boosters, adjuvants and combination of several antigens makes it economically unsuitable for cattle. Moreover, it is important to consider that the response observed in mice may not reflect the protection achieved in natural hosts after vaccination. Furthermore, to generate a strong and protective immune response that can mimic the natural infection from a combination of few proteins of the pathogen is a hard and complex challenge.

\subsection{Vector vaccines}

Alternatively, genes encoding immunodominant $B$. abortus antigens can be introduced into attenuated viruses or bacteria that serve as vector vaccines. $B$. abortus genes have been successfully expressed in viruses (Semliki Forest virus and Vaccinia virus) and bacteria (Escherichia coli, Ochrobactrum anthropi, Lactococcus lactis, Salmonella enterica subsp enterica serovar Typhimurium and B. abortus) $[16,20,26,28,35,38,44,86]$. Escherichia coli, O. anthropi (plus unmethylated CpG motifs) and L. lactis expressing $\mathrm{Cu} / \mathrm{Zn}$ SOD antigen of
B. abortus were able to elicit a Th1 immune response and to protect mice following challenge with virulent B. abortus $[20,28,44,86]$. Likewise, Semliki Forest virusbased vector carrying RNA encoding Brucella translation initiation factor 3 (IF3) showed a significant level of protection against a challenge with $B$. abortus 2308 in mice [35]. L7/L12 protein carried by S. enterica serovar typhimurium but not by Vaccinia virus conferred protective efficacy and immunogenicity [26,38]. Also, vaccinia virus carrying $18-\mathrm{kDa}$ OMP of $B$. abortus were not able to protect mice against a challenge with the virulent strain $B$. abortus 2308 [87].

The expression of $B$. abortus antigens on viral or bacterial vectors is a superior alternative to DNA and subunit vaccines, as it closely mimics the natural infection, allowing the modulation of the host immune response and the multiplication of the initial number of antigen copies within the host. However, despite not having some of the inconveniences observed in non-living vaccines, as multiple doses, need for adjuvant and high cost, other organisms expressing B. abortus proteins still need the perfect grouping of antigens, expressed in high amount to be effective. The amount of foreign protein expressed by the carrier organism needs to be able to promote a specific protection. Moreover, the use of viral platform implies in small chance that the vector DNA is integrated into the genome of the host cell. In addition, although promising most of these above vaccines have failed or have not been tested in cattle, the target species, so no conclusion could be drawn at this time.

\subsection{B. abortus recombinant mutants}

Another focus of research for new vaccines to protect against $B$. abortus infection has been the construction of RB51 recombinant mutants, which retain the rough phenotype and attenuation but have improved characteristics such as immunogenicity and protection against a challenge [17-19]. Hence, some studies have shown that the complementation of RB51 with a functional wboA gene (RB51WboA), which lead to the expression of O-side chain in its cytoplasm, or the overexpression of $\mathrm{Cu} / \mathrm{Zn}$ SOD protein (RB51SOD) results in significant enhancement of the vaccine efficacy against challenge with virulent B. abortus in mice $[17,18]$. Furthermore, the combination of these two genes in a single RB51 strain (RB51SOD/ $w b o A)$ also significantly increased the protective ability of this RB51 recombinant vaccine in mice and did not alter its desirable characteristics [19]. Nonetheless, this RB51recombinant strain was not as effective as the parental RB51 strain in calfhood vaccination of bison after challenge with 2308 [36].

Besides RB51, B. abortus strain 2308 has also been tested as recombinant mutant vaccine; the deletion of the gene $z n u A$, important protein for survival and normal 
growth under low $\mathrm{Zn}^{2+}$ concentrations, generated a mutant capable of conferring protection similar to S19 or RB51 against challenge with parental 2308 in mice [30]. Experiments in natural hosts, cattle, showed that the double gene deletion (htrA cycL) PHE1 was attenuated in the bovine host when compared to the virulent parental 2308 [88]. However, due the absence of a standard challenge study using this potential vaccine, the meaning of such data is unclear. Recombinant mutants based on deletion of $\mathrm{ABC}$ transporter ATPase (BAB1_0542) or phosphoglycerate kinase (pgk) gene of $B$. abortus 2308 also showed protection against challenge with virulent strain in mice and the critical role of these genes for full bacterial virulence $[89,90]$. In addition to the virulence attenuation, it is desired that these $B$. abortus mutants also show no interference with the diagnostics tests, hence genes associated to the smooth phenotype have been explored in the generation of deleted vaccines. Rough mutant generated by $w b o A$ gene deletion of S19 protected mice against challenge with 2308 and did not induce abortion in pregnant sheep, showing promising results to be explored in the future development of rough vaccines [91].

The improvement of the existing $B$. abortus vaccines or the creation of new attenuated vaccines by deletion or complementation of some genes seems to be the most promising direction to find a safer and more efficient substitute for the known $B$. abortus vaccines. Modified live vaccines are highly effective in comparison to killed vaccines. This is most likely due to strong and protective cellular immune response induced by live vaccines $[2,3]$. The use of this platform avoids the main disadvantages related to the non-living vaccines, as multiple delivery, low immunogenicity, need for adjuvants and high cost. Furthermore, $B$. abortus strains, even if genetically modified, can colonize, be immunogenic, and therefore perfectly simulate the natural infection. They are able to multiply within animals for a short period expressing in vivo protective antigens. The major advantage of this approach over the use of vectors is that recombinant mutants share most of proteins with $B$. abortus field strains, whereas carrier organisms are able of expressing only few Brucella antigens. However, a real concern on $B$. abortus mutant strains is the presence of antibiotic selection marker. The antibiotic marker is used in the screening of transformed clones, but it is not desirable in the final vaccine due to the potential of spreading antibiotic resistance genes. Options, as an RB51 leucine auxotroph, have been explored to avoid this issue [92]. Additionally, so far, there is no data available to exclude the possibility that these live mutants will not have similar safety and diagnostic issues as live strains, especially if made from smooth strains. Also, to move forwards in the control of bovine brucellosis, these recombinant mutants must be evaluated in cattle and other target animal species. There is still a worldwide need for a vaccine that is safe and highly efficacious in natural hosts, since the transmission of disease occurs from cattle to people. The results obtained in mice, although favorable for some vaccines, have to be interpreted according to their limitations, as they cannot be directly extrapolated to cattle.

On another point of view about the usefulness of $B$. abortus mutant as vaccines, S19 and RB51, the widely used $B$. abortus vaccines, has been investigated as potential vectors for heterologous protein expression, mainly using protective antigens important for other diseases of veterinary interest [93-96]. In this context, multivalent recombinant RB51 vaccines expressing Neospora caninum or M. bovis proteins have been shown to induce antigen specific immune response to heterologous antigens and, in the case of $N$. caninum, was also achieved significant level of protection in mice $[93,94]$. Likewise, S19 carrying the genes encoding for the heterologous antigens of Babebia bovis or $M$. bovis demonstrated successful specific cellular immune response to recombinant proteins in mouse model $[95,96]$. These above bivalent live modified $B$. abortus candidate vaccines need further evaluation as to their ability to induce protective immune response as well lack of interference in the diagnostic tests.

\section{Other B. abortus potential vaccines}

Besides $B$. abortus recombinants vaccines, also vaccines based on outer membrane vesicles (OMVs) has been exploited as an acellular alternative to live vaccines [97]. OMVs are bilayer membrane vesicles release by Gramnegative and Gram-positive bacteria, which have been associated to many processes such as release of virulent factors, DNA transfer, regulation of host immune response and survival in the host cell [98]. B. abortus OMVs are mainly composed for outer membrane proteins (Omps) and have been associated with modulation of host immune response by inhibition of TNF- $\alpha$ and IL-8 response, inhibition of IFN- $\gamma$ induced expression of MHC class II molecules on human monocytes and increase in expression of adhesion molecules [97-99]. A Brucella melitensis vaccine based on OMVs has been tested and showed promising results in BALB/c mice [100]. Furthermore, it is already available a vaccine based on OMVs, against meningococcus serogroup B (Neisseria meningitides) in some countries as Cuba, Norway and New Zealand [97]. Therefore, it is possible to speculate that an OMV vaccine against $B$. abortus has a great potential to be considered as part of the continuous efforts to reach safer and more effective $B$. abortus vaccine. Nonetheless, due to its high cost and laborious production, OMV is a more suitable approach for human vaccines, being impracticable for cattle bearing in mind the technologies currently available.

\section{Conclusions}

Vaccination is a determinant strategy for brucellosis control and eradication programs, therefore it has been the 
target of innumerous studies over decades. Nowadays, some effective vaccines are available to control the disease in cattle. S19 and RB51 are the officially approved $B$. abortus vaccine strains more widely and successfully used to prevent bovine brucellosis worldwide. However, due to some side effects shown by these current vaccines, plus the advances in recombinant DNA technology and the lack of a vaccine for humans, there is an on going extensive efforts focused on the development of new and better vaccines. Engineered vaccines have the potential to be the future of the bovine and human brucellosis control, but many studies are still needed to develop a better vaccine than the current vaccines in terms of safety, efficacy and other desirable characteristics. Moreover, it is important to consider that, mainly nonliving recombinant vaccines, also present important issues, as the requirement of multiple boosters, adjuvants, and optimal combination of antigens, besides usually inducing poor cellular immune response. In addition, although the excellent results observed for some recombinant vaccines in mice, very few of these candidate vaccines have been evaluated in cattle. The recent studies indicate that the future of a new $B$. abortus vaccine will be the construction of directed mutants, which exclude the drawbacks and simultaneously increase immunogenic characteristics presented by S19 and RB51. Furthermore, concerning the immune response induced after S19 and RB51 vaccination in cattle, as well as after RB51 revaccination, very little is understood. Efforts to find out the principal characteristics of the immune response triggered in cattle by the two most used and successful B. abortus vaccine strains are essential to try to establish an ideal vaccine. The definition of immune markers correlated with protection, by mathematical modeling or evaluation of the immune response in vaccine - challenge studies - would be very helpful in the screening of $B$. abortus candidate vaccines.

\section{Abbreviations}

Th1: Type 1 T helper; LPS: Lipopolysaccharide; CFU: Colony forming units; OPS: O-side chains; OMP: Outer membrane protein; Cu-Zn SOD: Cu/Zn superoxide dismutase; BFR: Bacterioferritin; BCG: Bacillus Calmette-Guerin; rCysk: Cysteine synthase A.

\section{Competing interests}

The authors declare that they have no competing interests.

\section{Authors' contributions}

EMSD wrote the paper. APL and NS critically reviewed the manuscript. All authors read and approved the final manuscript.

\section{Acknowledgements}

A.P. Lage were indebted to Conselho Nacional de Desenvolvimento Científico e Tecnológico - CNPq for his fellowship. EMSD thanks CNPq and Capes (Ciência Sem Fronteiras 8808-13) for her fellowship as well. APL lab was supported by CNPq, Fundação de Amparo à Pesquisa do Estado de Minas Gerais - Fapemig and FEP - MVZ Coordenação Preventiva.

\section{Author details}

'Departamento de Medicina Veterinária Preventiva, Escola de Veterinária, Laboratório de Bacteriologia Aplicada, Universidade Federal de Minas Gerais, Belo Horizonte, MG, Brazil. ²Department of Biomedical Sciences and Pathobiology, Center for Molecular Medicine and Infectious Diseases, Regional College of Veterinary Medicine, Virginia Polytechnic Institute and State University, Blacksburg, VA, USA.

Received: 21 December 2014 Accepted: 5 May 2015

Published online: 08 July 2015

\section{References}

1. Corbel MJ, Elberg SS, Cosivi O (2006) Brucellosis in humans and animals. World Health Organization, Geneva

2. Schurig G, Boyle S, Sriranganathan N (1995) Brucella abortus vaccine strain RB51: a brief review. Arch Med Vet 27:19-22

3. Ko J, Splitter GA (2003) Molecular host-pathogen interaction in brucellosis: current understanding and future approaches to vaccine development for mice and humans. Clin Microbiol Rev 16:65-78

4. Olsen SC, Stoffregen WS (2005) Essential role of vaccines in brucellosis control and eradication programs for livestock. Expert Rev Vaccines 4:915-928

5. Nicoletti P (1990) Vaccination. In: Nielsen K, Duncan JR (eds) Animal Brucellosis. CRC Press, Boca Raton

6. Poester FP, Goncalves VS, Paixao TA, Santos RL, Olsen SC, Schurig GG, Lage AP (2006) Efficacy of strain RB51 vaccine in heifers against experimental brucellosis. Vaccine 24:5327-5334

7. Olsen SC, Bricker B, Palmer MV, Jensen AE, Cheville NF (1999) Responses of cattle to two dosages of Brucella abortus strain RB51: serology, clearance and efficacy. Res Vet Sci 66:101-105

8. Thakur A, Pedersen LE, Jungersen G (2012) Immune markers and correlates of protection for vaccine induced immune responses. Vaccine 30:4907-4920

9. Miranda KL, Dorneles EM, Pauletti RB, Poester FP, Lage AP (2015) Brucella abortus S19 and RB51 vaccine immunogenicity test: evaluation of three mice (BALB/C, Swiss and CD-1 ${ }^{\oplus}$ ) and two challenge strains (544 and 2308). Vaccine 33:507-511

10. Garcia-Yoldi D, Le Fleche P, Marin CM, De Miguel MJ, Munoz PM, Vergnaud G, Lopez-Goni I (2007) Assessment of genetic stability of Brucella melitensis Rev 1 vaccine strain by multiple-locus variable-number tandem repeat analysis. Vaccine 25:2858-2862

11. Miranda KL, Poester FP, Minharro S, Dorneles EM, Stynen AP, Lage AP (2013) Evaluation of Brucella abortus S19 vaccines commercialized in Brazil: immunogenicity, residual virulence and MLVA15 genotyping. Vaccine 31:3014-3018

12. Dorneles EM, de Faria AP, Pauletti RB, Santana JA, Caldeira GA, Heinemann MB, Titze-de-Almeida R, Lage AP (2013) Genetic stability of Brucella abortus S19 and RB51 vaccine strains by multiple locus variable number tandem repeat analysis (MLVA16). Vaccine 31:4856-4859

13. Oliveira SC, Harms JS, Banai M, Splitter GA (1996) Recombinant Brucella abortus proteins that induce proliferation and gamma-interferon secretion by CD4+ T cells from Brucella-vaccinated mice and delayed-type hypersensitivity in sensitized guinea pigs. Cell Immunol 172:262-268

14. Oliveira SC, Splitter GA (1996) Immunization of mice with recombinant $\mathrm{L} 7 / \mathrm{L} 12$ ribosomal protein confers protection against Brucella abortus infection. Vaccine 14:959-962

15. Vemulapalli R, Duncan AJ, Boyle SM, Sriranganathan N, Toth TE, Schurig GG (1998) Cloning and sequencing of yajC and secD homologs of Brucella abortus and demonstration of immune responses to YajC in mice vaccinated with B. abortus RB51. Infect Immun 66:5684-5691

16. Vemulapalli R, Cravero S, Calvert CL, Toth TE, Sriranganathan N, Boyle SM, Rossetti OL, Schurig GG (2000) Characterization of specific immune responses of mice inoculated with recombinant vaccinia virus expressing an 18-kilodalton outer membrane protein of Brucella abortus. Clin Diagn Lab Immunol 7:114-118

17. Vemulapalli R, He Y, Buccolo LS, Boyle SM, Sriranganathan N, Schurig GG (2000) Complementation of Brucella abortus RB51 with a functional wboA gene results in O-antigen synthesis and enhanced vaccine efficacy but no change in rough phenotype and attenuation. Infect Immun 68:3927-3932

18. Vemulapalli R, He Y, Cravero S, Sriranganathan N, Boyle SM, Schurig GG (2000) Overexpression of protective antigen as a novel approach to enhance vaccine efficacy of Brucella abortus strain RB51. Infect Immun 68:3286-3289 
19. Vemulapalli R, Contreras A, Sanakkayala N, Sriranganathan N, Boyle SM, Schurig GG (2004) Enhanced efficacy of recombinant Brucella abortus RB51 vaccines against $B$. melitensis infection in mice. Vet Microbiol 102:237-245

20. He Y, Vemulapalli R, Schurig GG (2002) Recombinant Ochrobactrum anthropi expressing Brucella abortus Cu, Zn superoxide dismutase protects mice against $B$. abortus infection only after switching of immune responses to Th1 type. Infect Immun 70:2535-2543

21. Al-Mariri A, Tibor A, Mertens P, De Bolle X, Michel P, Godefroid J, Walravens K Letesson JJ (2001) Protection of BALB/C mice against Brucella abortus 544 challenge by vaccination with bacterioferritin or P39 recombinant proteins with CpG oligodeoxynucleotides as adjuvant. Infect Immun 69:4816-4822

22. Al-Mariri A, Tibor A, Mertens P, De Bolle X, Michel P, Godfroid J, Walravens K, Letesson JJ (2001) Induction of immune response in BALB/C mice with a DNA vaccine encoding bacterioferritin or P39 of Brucella spp. Infect Immun 69:6264-70

23. Velikovsky CA, Cassataro J, Giambartolomei GH, Goldbaum FA, Estein S, Bowden RA, Bruno L, Fossati CA, Spitz M (2002) A DNA vaccine encoding lumazine synthase from Brucella abortus induces protective immunity in BALB/c mice. Infect Immun 70:2507-2511

24. Velikovsky CA, Goldbaum FA, Cassataro J, Estein S, Bowden RA, Bruno L, Fossati CA, Giambartolomei GH (2003) Brucella lumazine synthase elicits a mixed Th1-Th2 immune response and reduces infection in mice challenged with Brucella abortus 544 independently of the adjuvant formulation used. Infect Immun 71:5750-5755

25. Onate AA, Cespedes S, Cabrera A, Rivers R, Gonzalez A, Munoz C, Folch H, Andrews E (2003) A DNA vaccine encoding Cu, Zn superoxide dismutase of Brucella abortus induces protective immunity in BALB/C mice. Infect Immun 71:4857-4861

26. Baloglu S, Boyle SM, Vemulapalli R, Sriranganathan N, Schurig GG, Toth TE (2005) Immune responses of mice to vaccinia virus recombinants expressing either Listeria monocytogenes partial listeriolysin or Brucella abortus ribosomal L7/L12 protein. Vet Microbiol 109:11-17

27. Luo D, Ni B, Li P, Shi W, Zhang S, Han Y, Mao L, He Y, Wu Y, Wang X (2006) Protective immunity elicited by a divalent DNA vaccine encoding both the L7/L12 and Omp16 genes of Brucella abortus in BALB/C mice. Infect Immun 74:2734-2741

28. Andrews $E$, Salgado $P$, Folch $H$, Onate A (2006) Vaccination with live Escherichia coli expressing Brucella abortus Cu/Zn superoxide-dismutase: II. Induction of specific CD8+ cytotoxic lymphocytes and sensitized CD4+ IFN-gamma-producing cell. Microbiol Immunol 50:389-393

29. Gonzalez-Smith A, Vemulapalli R, Andrews E, Onate A (2006) Evaluation of Brucella abortus DNA vaccine by expression of $\mathrm{Cu}-\mathrm{Zn}$ superoxide dismutase antigen fused to IL-2. Immunobiology 211:65-74

30. Yang X, Becker T, Walters N, Pascual DW (2006) Deletion of znuA virulence factor attenuates Brucella abortus and confers protection against wild-type challenge. Infect Immun 74:3874-3879

31. Delpino MV, Estein SM, Fossati CA, Baldi PC, Cassataro J (2007) Vaccination with Brucella recombinant DnaK and SurA proteins induces protection against Brucella abortus infection in BALB/C mice. Vaccine 25:6721-6729

32. Yu DH, Hu XD, Cai H (2007) A combined DNA vaccine encoding BCSP31, SOD, and L7/L12 confers high protection against Brucella abortus 2308 by inducing specific CTL responses. DNA Cell Biol 26:435-443

33. Yu DH, Li M, Hu XD, Cai H (2007) A combined DNA vaccine enhances protective immunity against Mycobacterium tuberculosis and Brucella abortus in the presence of an IL-12 expression vector. Vaccine 25:6744-6754

34. Hu XD, Yu DH, Chen ST, Li SX, Cai H (2009) A combined DNA vaccine provides protective immunity against Mycobacterium bovis and Brucella abortus in cattle. DNA Cell Biol 28:191-199

35. Cabrera A, Saez D, Cespedes S, Andrews E, Onate A (2009) Vaccination with recombinant Semliki Forest virus particles expressing translation initiation factor 3 of Brucella abortus induces protective immunity in BALB/C mice. Immunobiology 214:467-474

36. Olsen SC, Boyle SM, Schurig GG, Sriranganathan NN (2009) Immune responses and protection against experimental challenge after vaccination of bison with Brucella abortus strain RB51 or RB51 overexpressing superoxide dismutase and glycosyltransferase genes. Clin Vaccine Immunol 16:535-540

37. Pasquevich KA, Estein SM, Garcia Samartino C, Zwerdling A, Coria LM, Barrionuevo P, Fossati CA, Giambartolomei GH, Cassataro J (2009) Immunization with recombinant Brucella species outer membrane protein Omp16 or Omp19 in adjuvant induces specific CD4+ and CD8+ T cells as well as systemic and oral protection against Brucella abortus infection. Infect Immun 77:436-445
38. Zhao Z, Li M, Luo D, Xing L, Wu S, Duan Y, Yang P, Wang X (2009) Protection of mice from Brucella infection by immunization with attenuated Salmonella enterica serovar typhimurium expressing A L7/L12 and BLS fusion antigen of Brucella. Vaccine 27:5214-5219

39. Pasquevich KA, Ibanez AE, Coria LM, Garcia Samartino C, Estein SM, Zwerdling A, Barrionuevo P, Oliveira FS, Seither C, Warzecha H, Oliveira SC, Giambartolomei GH, Cassataro J (2011) An oral vaccine based on U-Omp19 induces protection against B. abortus mucosal challenge by inducing an adaptive IL-17 immune response in mice. PLoS One 6:e16203

40. Singha $H$, Mallick Al, Jana C, Fatima N, Owais M, Chaudhuri P (2011) Co-immunization with interlukin-18 enhances the protective efficacy of liposomes encapsulated recombinant $\mathrm{Cu}$-Zn superoxide dismutase protein against Brucella abortus. Vaccine 29:4720-4727

41. Verma SK, Jain S, Kumar S (2012) Immunogenicity and protective potential of a bacterially expressed recombinant dihydrolipoamide succinyltransferase (rE2o) of Brucella abortus in BALB/C mice. World J Microbiol Biotechnol 28:2487-2495

42. Sislema-Egas F, Cespedes S, Fernandez P, Retamal-Diaz A, Saez D, Onate A (2012) Evaluation of protective effect of DNA vaccines encoding the BAB1_0263 and BAB1_0278 open reading frames of Brucella abortus in BALB/C mice. Vaccine 30:7286-7291

43. Lim JJ, Kim DH, Lee JJ, Kim DG, Min W, Lee HJ, Rhee MH, Kim S (2012) Protective effects of recombinantBrucella abortusOmp28 against infection with a virulent strain of Brucella abortus544 in mice. J Vet Sci 13:287-292

44. Saez D, Fernandez P, Rivera A, Andrews E, Onate A (2012) Oral immunization of mice with recombinant Lactococcus lactis expressing $\mathrm{Cu}$, Zn superoxide dismutase of Brucella abortus triggers protective immunity. Vaccine 30:1283-1290

45. Goel D, Rajendran V, Ghosh PC, Bhatnagar R (2013) Cell mediated immune response after challenge in Omp25 liposome immunized mice contributes to protection against virulent Brucella abortus 544. Vaccine 31:1231-1237

46. Jain S, Afley P, Kumar S (2013) Immunological responses to recombinant cysteine synthase A of Brucella abortus in BALB/C mice. World J Microbiol Biotechnol 29:907-913

47. Manthei CA (1959) Summary of controlled research with strain 19, Proceedings 63rd Ann Meet US Livestock Sanitary Association.

48. Buck JM (1930) Studies on vaccination during calfhood to prevent bovine infectious abortion. J Agri Res 41:667-689

49. Graves RR (1943) The story of John M. Buck's and Matilda's contribution to the cattle industry J Am Vet Med Assoc 102:193-195

50. Jones FM, Hooper JA (1976) Brucella abortus strain 19 calfhood vaccination a review. Southwest Vet 29:219-225

51. McDiarmid A (1957) The degree and duration of immunity in cattle resulting from vaccination with S. $19 \mathrm{Br}$. abortus vaccine and its implication in the future control and eventual eradication of Brucellosis. Vet Rec 69:877-879

52. Koh SH, Morley FH (1981) The effect of calfhood vaccination with strain 19 on the serological diagnosis and eradication of bovine brucellosis. Aust Vet J 57:551-553

53. Mingle CK, Manthei CA, Jasmin AM (1941) The stability of reduced virulence exhibited by Brucella abortus strain 19. J Am Vet Med Assoc 99:203-205

54. Meyer ME, Nelson CJ (1969) Persistence of Brucella abortus, strain 19 infection in immunized cattle. Proc Annu Meet U S Anim Health Assoc 73:159-165

55. Breitmeyer RE, Hird DW, Carpenter TE (1992) Serologic and bacteriologic test results after adult vaccination with strain 19 in three dairy herds infected with brucellosis. J Am Vet Med Assoc 200:806-811

56. Nicoletti P (1981) Prevalence and persistence of Brucella abortus strain 19 infections and prevalence of other biotypes in vaccinated adult dairy cattle. J Am Vet Med Assoc 178:143-145

57. Corner LA, Alton GG (1981) Persistence of Brucella abortus strain 19 infection in adult cattle vaccinated with reduced doses. Res Vet Sci 31:342-344

58. Lambert G, Manthei CA, Deyoe BL (1963) Studies on Brucella abortus infection in bulls. Am J Vet Res 24:1152-1157

59. Schurig GG, Roop RM 2nd, Bagchi T, Boyle S, Buhrman D, Sriranganathan N (1991) Biological properties of RB51; a stable rough strain of Brucella abortus. Vet Microbiol 28:171-188

60. Cheville NF, Stevens MG, Jensen AE, Tatum FM, Halling SM (1993) Immune responses and protection against infection and abortion in cattle experimentally vaccinated with mutant strains of Brucella abortus. Am J Vet Res 54:1591-1597

61. Olsen SC (2000) Immune responses and efficacy after administration of a commercial Brucella abortus strain RB51 vaccine to cattle. Vet Ther 1:183-191

62. Lord VR, Schurig GG, Cherwonogrodzky JW, Marcano MJ, Melendez GE (1998) Field study of vaccination of cattle with Brucella abortus strains RB51 and 19 under high and low disease prevalence. Am J Vet Res 59:1016-1020 
63. Dorneles EM, Santana JA, Alves TM, Pauletti RB, Mol JP, Heinemann MB, Lage AP (2014) Genetic stability of Brucella abortus isolates from an outbreak by multiple-locus variable-number tandem repeat analysis (MLVA16). BMC Microbiol 14:186

64. Cheville NF, Olsen SC, Jensen AE, Stevens MG, Palmer MV, Florance AM (1996) Effects of age at vaccination on efficacy of Brucella abortus strain RB51 to protect cattle against brucellosis. Am J Vet Res 57:1153-1156

65. Palmer MV, Cheville NF, Jensen AE (1996) Experimental infection of pregnant cattle with the vaccine candidate Brucella abortus strain RB51: pathologic, bacteriologic, and serologic findings. Vet Pathol 33:682-691

66. Palmer MV, Olsen SC, Cheville NF (1997) Safety and immunogenicity of Brucella abortus strain RB51 vaccine in pregnant cattle. Am J Vet Res 58:472-477

67. Martins H, Garin-Bastuji B, Lima F, Flor L, Pina Fonseca A, Boinas F (2009) Eradication of bovine brucellosis in the Azores, Portugal-Outcome of a 5-year programme (2002-2007) based on test-and-slaughter and RB51 vaccination. Prev Vet Med 90:80-89

68. Samartino LE, Fort M, Gregoret R, Schurig GG (2000) Use of Brucella abortus vaccine strain RB51 in pregnant cows after calfhood vaccination with strain 19 in Argentina. Prev Vet Med 45:193-199

69. Edmonds MD, Schurig GG, Samartino LE, Hoyt PG, Walker JV, Hagius SD, Elzer PH (1999) Biosafety of Brucella abortus strain RB51 for vaccination of mature bulls and pregnant heifers. Am J Vet Res 60:722-725

70. Ashford DA, di Pietra J, Lingappa J, Woods C, Noll H, Neville B, Weyant R, Bragg SL, Spiegel RA, Tappero J, Perkins BA (2004) Adverse events in humans associated with accidental exposure to the livestock brucellosis vaccine RB51. Vaccine 22:3435-3439

71. Olsen SC, Stevens MG, Cheville NF, Schurig G (1997) Experimental use of a dot-blot assay to measure serologic responses of cattle vaccinated with Brucella abortus strain RB51. J Vet Diagn Invest 9:363-367

72. Nielsen K, Smith P, Yu W, Nicoletti P, Elzer P, Vigliocco A, Silva P, Bermudez R, Renteria T, Moreno F, Ruiz A, Massengill C, Muenks Q, Kenny K, Tollersrud T, Samartino L, Conde S, Draghi De Benitez G, Gall D, Perez B, Rojas X (2004) Enzyme immunoassay for the diagnosis of brucellosis: chimeric Protein A-Protein $\mathrm{G}$ as a common enzyme labeled detection reagent for sera for different animal species. Vet Microbiol 101:123-129

73. Stevens MG, Olsen SC, Cheville NF (1995) Comparative analysis of immune responses in cattle vaccinated with Brucella abortus strain 19 or strain RB51. Vet Immunol Immunopathol 44:223-235

74. Luna-Martinez JE, Mejia-Teran C (2002) Brucellosis in Mexico: current status and trends. Vet Microbiol 90:19-30

75. Dorneles EM, Teixeira-Carvalho A, Araujo MS, Lima GK, Martins-Filho OA, Sriranganathan N, Lage AP (2014) T lymphocytes subsets and cytokine pattern induced by vaccination against bovine brucellosis employing S19 calfhood vaccination and adult RB51 revaccination. Vaccine 32:6034-6038

76. He Y, Vemulapalli R, Zeytun A, Schurig GG (2001) Induction of specific cytotoxic lymphocytes in mice vaccinated with Brucella abortus RB51. Infect Immun 69:5502-5508

77. McEwen AD, Samuel JMD (1955) Brucella abortus: heat stable protective antigen revealed by adjuvant and present in a rough variant strain 45/20: immunization experiments on guinea pigs. Vet Rec 67:546-548

78. McEwen AD (1940) Experiments on contagious abortion. The immunity of cattle inoculated with vaccines of graded virulence. Vet Rec 52:815

79. Cunningham B (1977) The effect of immaturity of the calf on immunological responses to strain 19 and killed 45/20 adjuvant vaccines. Vet Rec 101:283-285

80. Woodard LF, Jasman RL (1983) Comparative efficacy of an experimental S45/20 bacterin and a reduced dose of strain 19 vaccine against bovine brucellosis. Am J Vet Res 44:907-910

81. Schurig GG, Hammerberg C, Finkler BR (1984) Monoclonal antibodies to Brucella surface antigens associated with the smooth lipopolysaccharide complex. Am J Vet Res 45:967-971

82. Ivanov AV, Salmakov KM, Olsen SC, Plumb GE (2011) A live vaccine from Brucella abortus strain 82 for control of cattle brucellosis in the Russian Federation. Anim Health Res Rev 12:113-121

83. Salmakov KM, Fomin AM, Plotnikova EM, Safina GM, Galimova GM, Salmakova AV, Ivanov AV, Panin AN, Sklyarov OD, Shumilov KV, Klimanov AI (2010) Comparative study of the immunobiological properties of live brucellosis vaccines. Vaccine 28(Suppl 5):F35-40

84. Li X, Xu J, Xie Y, Qiu Y, Fu S, Yuan X, Ke Y, Yu S, Du X, Cui M, Chen Y, Wang T, Wang Z, Yu Y, Huang K, Huang L, Peng G, Chen Z, Wang Y (2012) Vaccination with recombinant flagellar proteins FlgJ and FliN induce protection against Brucella abortus 544 infection in BALB/c mice. Vet Microbiol 161:137-144
85. Fu S, Xu J, Li X, Xie Y, Qiu Y, Du X, Yu S, Bai Y, Chen Y, Wang T, Wang Z, Yu Y, Peng G, Huang K, Huang L, Wang Y, Chen Z (2012) Immunization of mice with recombinant protein $\mathrm{CobB}$ or AsnC confers protection against Brucella abortus infection. PLoS One 7:e29552

86. Onate AA, Vemulapalli R, Andrews E, Schurig GG, Boyle S, Folch H (1999) Vaccination with live Escherichia coli expressing Brucella abortus $\mathrm{Cu} / \mathrm{Zn}$ superoxide dismutase protects mice against virulent B. abortus. Infect Immun 67:986-988

87. Vemulapalli R, Cravero S, Calvert CL, Toth TE, Sriranganathan N, Boyle SM, Rossetti OL, Schurig GG (2000) Characterization of specific immune responses of mice inoculated with recombinant vaccinia virus expressing an 18-kilodalton outer membrane protein of Brucella abortus. Clin Vaccine Immunol 7:114-118

88. Edmonds M, Booth N, Hagius S, Walker J, Enright F, Roop RM 2nd, Elzer P (2000) Attenuation and immunogenicity of a Brucella abortus htrA cycL double mutant in cattle. Vet Microbiol 76:81-90

89. Zhang M, Han X, Liu H, Tian M, Ding C, Song J, Sun X, Liu Z, Yu S (2013) Inactivation of the ABC transporter ATPase gene in Brucella abortus strain 2308 attenuated the virulence of the bacteria. Vet Microbiol 164:322-329

90. Trant CG, Lacerda TL, Carvalho NB, Azevedo V, Rosinha GM, Salcedo SP, Gorvel JP, Oliveira SC (2010) The Brucella abortus phosphoglycerate kinase mutant is highly attenuated and induces protection superior to that of vaccine strain 19 in immunocompromised and immunocompetent mice. Infect Immun 78:2283-2291

91. Wang Z, Niu J, Wang S, Lv Y, Wu Q (2013) In vivo differences in the virulence, pathogenicity, and induced protective immunity of wboA mutants from genetically different parent Brucella spp. Clin Vaccine Immunol 20:174-180

92. Rajasekaran P, Seleem MN, Contreras A, Purwantini E, Schurig GG, Sriranganathan N, Boyle SM (2008) Brucella abortus strain RB51 leucine auxotroph as an environmentally safe vaccine for plasmid maintenance and antigen overexpression. Applied Environ Microbiol 74:7051-7055

93. Vemulapalli R, He Y, Boyle SM, Sriranganathan N, Schurig GG (2000) Brucella abortus strain RB51 as a vector for heterologous protein expression and induction of specific Th1 type immune responses. Infect Immun 68:3290-3296

94. Ramamoorthy S, Sanakkayala N, Vemulapalli R, Jain N, Lindsay DS, Schurig GS, Boyle SM, Sriranganathan N (2007) Prevention of vertical transmission of Neospora caninum in C57BL/6 mice vaccinated with Brucella abortus strain RB51 expressing N. caninum protective antigens. Int J Parasitol 37:1531-1538

95. Sabio y García JV, Bigi F, Rossetti O, Campos E (2010) Expression of MPB83 from Mycobacterium bovis in Brucella abortus S19 induces specific cellular immune response against the recombinant antigen in $B A L B / C$ mice. Microbes Infect 12:1236-1243

96. Sabio y García JV, Farber M, Carrica M, Cravero S, Macedo GC, Bigi F, Oliveira SC, Rossetti O, Campos E (2008) Expression of Babesia bovis rhoptry-associated protein 1 (RAP1) in Brucella abortus S19. Microbes Infect 10:635-641

97. Avila-Calderón E, Araiza-Villanueva M, Cancino-Diaz J, López-Villegas E, Sriranganathan N, Boyle S, Contreras-Rodríguez A (2015) Roles of bacterial membrane vesicles. Arch Microbiol 197:1-10

98. Pollak CN, Delpino MV, Fossati CA, Baldi PC (2012) Outer membrane vesicles from Brucella abortus promote bacterial internalization by human monocytes and modulate their innate immune response. PLoS One 7:e50214

99. Lamontagne J, Butler H, Chaves-Olarte E, Hunter J, Schirm M, Paquet C, Tian M, Kearney P, Hamaidi L, Chelsky D, Moriyon I, Moreno E, Paramithiotis E (2007) Extensive cell envelope modulation is associated with virulence in Brucella abortus. J Proteome Res 6:1519-1529

100. Jain-Gupta N, Contreras-Rodriguez A, Vemulapalli R, Witonsky SG, Boyle SM, Sriranganathan N (2012) Pluronic P85 enhances the efficacy of outer membrane vesicles as a subunit vaccine against Brucella melitensis challenge in mice. FEMS Immunol Med Microbiol 66:436-444 